\title{
Variations in Motor Conduction Velocity Produced by Acute Changes of the Metabolic State in Diabetic Patients
}

\author{
G. GREGERSEN
}

Second Clinic of Internal Medicine and Department of Neurology, Aarhus University School of Medicine, Aarhus, Denmark

Received: January 15, 1968

Summary. Repeated measurements of motor conduction velocity in 14 primarily untreated diabetics showed a clear improvement in nerve-function during insulin treatment. - Similar results could not be produced by measuring the threshold for vibration sense.

Variations de la vitesse de conduction des nerfs moteurs provoquées par des modifications aiguës de l'état métabolique chez des diabétiques

Résumé. De nombreuses mesures de la vitesse de conduction des nerfs moteurs chez 14 diabétiques n'ayant subi aucune thérapeutique médicamenteuse, ont montré une amélioration évidente du fonctionnement nerveux pendant la durée du traitement à l'insuline, et une détérioration après l'arrêt du traitement. - Des résultats similaires n'ont pas pu être obtenus en mesurant le seuil de la perception vibratoire.
Veränderungen der motorischen Leitgeschwindigkeit während akuter Stoffwechselschwankungen bei Diabetikern

Zusammenfassung. Bei wiederholter Messung der motorischen Leitgeschwindigkeit bei 14 ursprünglich unbehandelten Diabetikern konnte ein Anstieg der Leitgeschwindigkeit während der Behandlung mit Insulin und ein erneuter Abfall nach Unterbrechung der Therapie nachoewiesen werden. - Die Schwelle der Vibrationsempfindung veränderte sich hingegen unter der Insulinbehandlung nicht nachweisbar.

Key-words: Motor conduction velocity, vibratory perception threshold, diabetes mellitus, control, insulin. variations in nerve function.
It is generally accepted that the various manifestations of diabetic angiopathy, such as retinopathy and nephropathy, are not influenced by acute changes in the metabolic state. The same is not true concerning diabetic neuropathy.

According to the experience of many physicians and investigators who have dealt with diabetic neuropathy, impressive changes in the manifestations of the neuropathy can be produced by variations in the metabolic state. However, the observations that have been published, are conflicting and often based on ill-defined clinical evaluations.

The object of the present work has been to create a better basis for our conception concerning the influence of the momentary metabolic state upon nervous function in diabetics, using quantitative neurophysiological measurements.

\section{Material and Methods}

Fourteen hospitalized patients with diabetes mellitus 5 aged $53-69$ years and 9 aged $12-41$ years, were studied. One patient, age 56, had had diabetes for 7 years and had been previously treated with insulin for short periods. However for the last 4 years, he had neglected control and treatment. He was also the only patient in the group showing retinopathy and clinical signs of neuropathy. The remaining 13 patients had recently-diagnosed and untreated diabetes. None of them had clinical symptoms of neuropathy. Blood glucose (o-toluidine method) was measured thrice daily: fasting in the morning, just after the midday meal and again late in the afternoon. $24 \mathrm{~h}$ urine was examined quantitatively for glucose and qualitatively for acetone and acetoacetic acid. When untreated, all the patients had high blood glucose levels throughout the $24 \mathrm{~h}$, but they were ambulatory and in good general condition. Nine of them had slight ketonuria.

Before treatment with insulin was started, measurements of the motor conduction velocity (MCV) in the peroneal nerve on both sides were made, by stimulating the nerve at the ankle and at the capitulum fibulae and recording the muscle potential via coaxial needle electrodes. The vibratory perception threshold (VPT) was measured on both great toes with a biothesiometer. A more detailed description of the tecniques and normal values will be found in earlier papers (GreGERSEN, 1967; GREGERSEN, 1968a). All the measurements were repeated once after at least one day's interval, and the average value of these two measurements used as the starting point.

After the initial measurements, the patients were put on a diet, and insulin given in order to bring the blood glucose level as near normal as possible throughout the day and to make the urine free of sugar. This treatment was continued under close supervision for a shorter or longer period. Slight insulin reactions frequently occurred, but severe reactions were not seen. Except in one case all the patients gained weight quickly after initiation of treatment, average $3.7 \mathrm{~kg}$.

During insulin treatment the $\mathrm{MCV}$ in both peroneal nerves and the VPT of both great toes were followed by repeated measurements, usually with intervals of 2-3 days. For practical reasons it was possible to follow two of the patients for only five days. The rest of the patients were followed from $8-35$ days. 

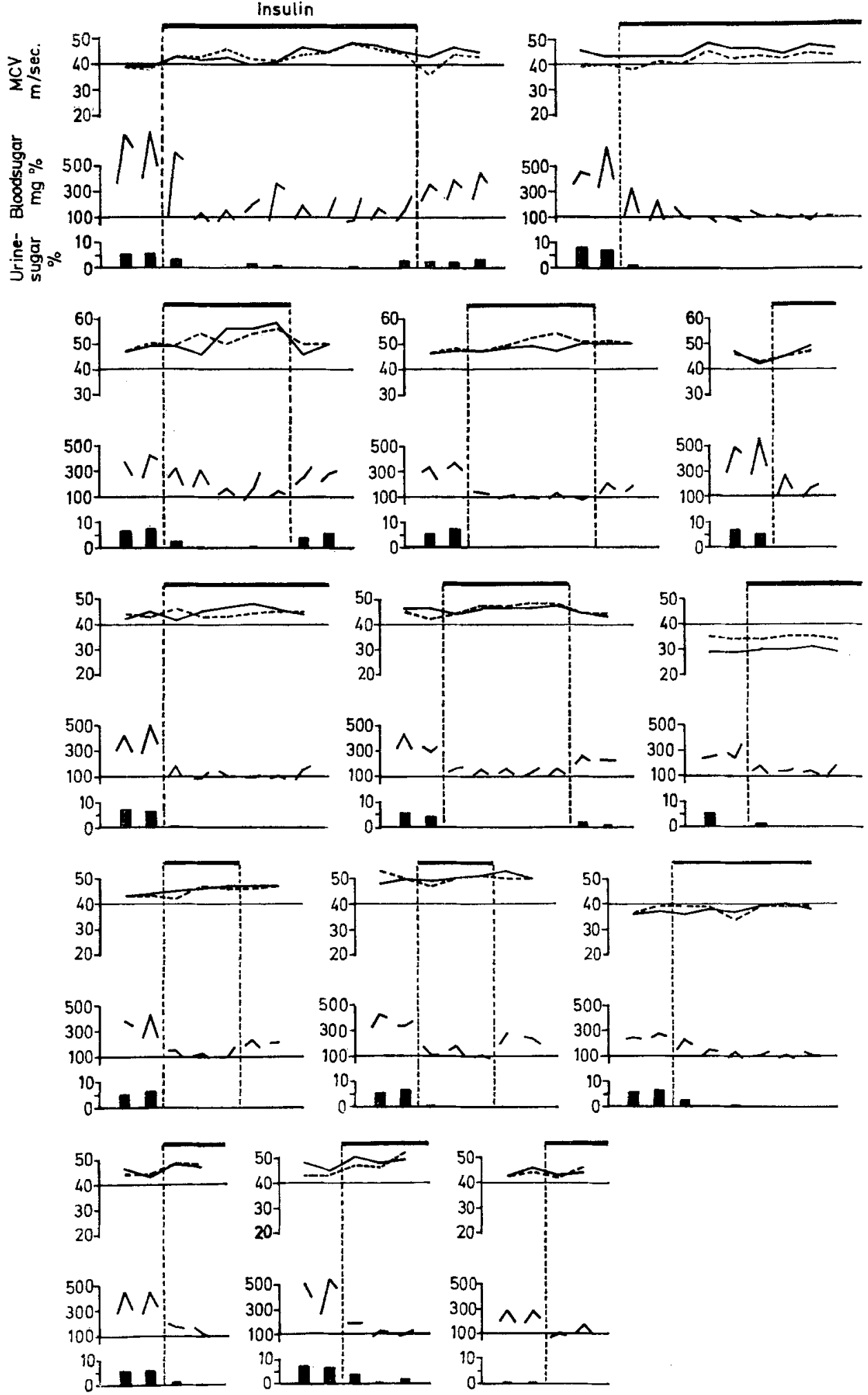

Fig. 1. Motor conduction velocity (MCV), blood sugar (3 times a day) and urine sugar before, during and after insulin treatment in 14 diabetics. The last diagram in the third row is from the patient with clinical neuropathy. MCV was measured in both right and left peroneal nerves. Right - Left ..... 
In 6 cases it was possible to withdraw insulin treatment and follow the patients with the same measurements, while the 24-h blood glucose level rose.

\section{Results}

Fig. 1 shows consecutive measurements of MCV in the peroneal nerves before, during and after insulin treatment in all 14 patients. A tendency for an increase in the MCV during treatment is observed in most of the cases. The values fall again in several cases after withdrawal of treatment.

Fig. 2 shows much more clearly the changes ( $\Delta$ $\mathrm{MCV}$ ) in all 28 peroneal nerves during the period of insulin treatment in proportion to the average of two values obtained before treatment. It is seen that nearly

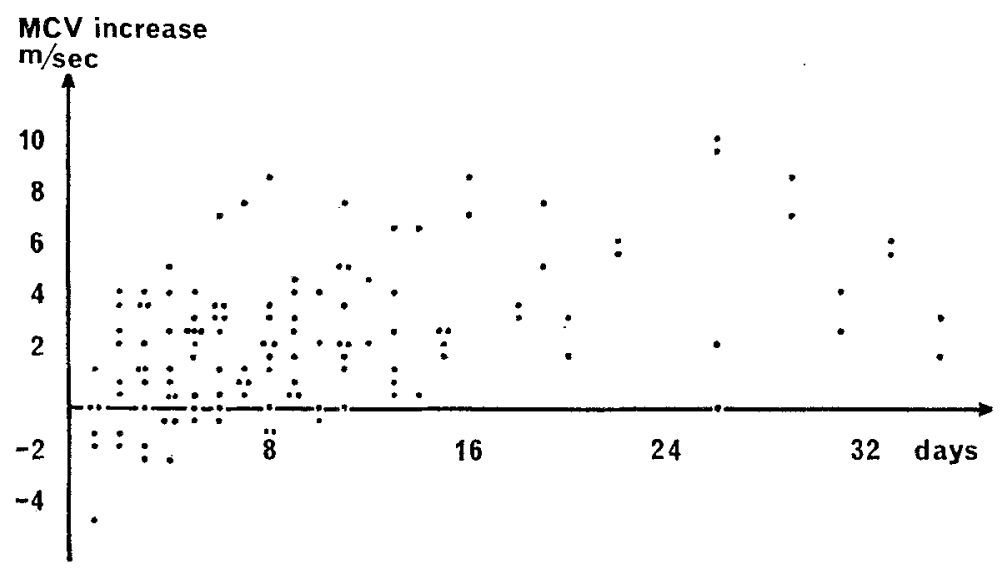

Fig. 2. $\Delta \mathrm{MCV}$ in the course of insulin treatment (28 peroneal nerves) ment. obtained during insulin treatment, and as can be seen, most of the values are lower than during treatment.

The same comparisons were done with the VPT on the great toes as a parameter, but here it was not possible to show an improvement during insulin treat-

Neither was it possible by daily clinical evaluation of the deep reflexes on the lower extremities to observe any changes during insulin treatment. Normal, brisk or weak reflexes were unchanged throughout the experiment.

\section{Discussion}

Many authors have been convinced of the significance of the metabolic status for diabetic neuropathy on the basis of clinical observations of symptoms regressing during intensication of treatment of the metabolic disease.

JORDAN (1936) introduced the name "hyperglycaemic type" of diabetic neuritis for symptoms such as nocturnal cramps in the calf, pain and paraesthesia that promptly disappear when treatment was started. In addition, he often noticed a regression of symptoms even in more severe forms of diabetic neuropathy after starting treatment. Similar reports have come from Gregory and LindLey (1947), Schumar and Gilpin (1954), GarlaNd and TaverNER (1953), Garlañd (1955), Azerad and coworkers (1961), REDwood (1962), and FRY and coworkers (1962) among others. On the other hand there have also been reports of cases, where treatment of the diabetes had no effect or even aggravated the symptoms of neuropathy (SkIllern and LockHart, 1959; Ellenberg, 1959; Gremibaum, 1964).

Many attempts have been made to evaluate the significance of metabolic control on clinical diabetic neuropathy by comparing different groups of patients in retrospective studies. The results have been conflicting and will not be discussed here.

The only prospective experimental study of a measurable nerve function in diabetics during acute change in carbohydrate-status seems to be that of GUYTONs from 1961. In one patient, recovering from diabetic coma, he demonstrated a distinct increase in motor conduction velocity. However, he was not able to show a change in MCV in 5 other diabetics whose insulin had been discontinued for up to 2 days.

The present investigation of a larger number of patients clearly shows that acute changes in actual metabolic state in diabetics affects nervous function, even when there is no subjective feeling or objective signs of illness.

In animal experiments Eurasson (1964) found decreased nerve conduction velocity in alloxan-diabetic and pancreatcctomized rats, but under the circum- peroneal nerves as shown in Fig. 3. The changes in MCV have been put in proportion to the last value all the values obtained exceed the starting point, only a few of them being lower in the first days of treat ment. The pattern is the same for patients below and years of age.

In the 6 patients where insulin treatment wa again discontinued experimenti causa and measurements repeated, a change in MCV was seen in the 12 
stances given was not able to reverse the decrease by insulin treatment.

The results obtained in the present work fit in with the difference in nerve-function demonstrated between poorly-regulated and well-regulated diabetics during experimental ischaemia (STEINESs 1961; GreGERSEN, $1968 \mathrm{c})$. They explain why nerve function is inferior to the normal even after a very short duration of diabetes (GREGERSEN, 1967, 1968a, 1968b), where diabetic angiopathy is unlikely to play a part.

In the present study different results were obtained by measuring MCV and VPT. However it can be assumed that MCV is a better parameter than biothesiometry under the conditions employed. The conduction of motor action potentials is a more simple function than perception of a sensory modality, which may be a resultant of both excitatory and inhibitory fibres, both subjected to the influence of changes in metabolic status (MELzAK and WALL, 1965).

The reason for increases in MCV when the blood glucose level is normalized in diabetics is quite unknown. We know from our own studies that morphological changes in peripheral nerves from young patients with recently diagnosed diabetes are not uncommon (RESKE-NIELSEN, GREGERSEN and HARMSEN, to be published). Biscroff (1967) found morphological changes in nerves from hamsters after diabetes of short duration. However, we do not know if such changes are reversible. From Fig. 2 it appears that a reliable increase in MCV is first seen after 2 or 3 days treatment, so that some morphological repair has had time to occur.

Reversible biochemical changes in nerve-tissue have not yet been demonstrated in patients with recent diabetes. Alterations of hydration and electrolyteconcentrations could play a part, although it has been difficult to show (SIMPSoN, 1962). It is well known, that insulin stimulates the uptake of glucose and oxygen in the peripheral nerve (RAFAELSEN, 1958; HELLER and Hesse, 1960; Freud and Adams 1964). Synthesis of cholesterol is decreased and synthesis of fatty acids increased in the nerves of alloxan-diabetic rats (EuIasson and Hugres, 1960). Recently the demonstration of accumulation of sorbitol, fructose and glucose in alloxan-diabetic nerves has drawn attention (STEWART et al., 1966; GABBAY et al., 1966).

Thus there can be no doubt that an abnormality of the peripheral nerves takes place early in recent, untreated diabetes. This can be demonstrated neurophysiologically and histologically, but remains to be elucidated by biochemical methods.

As shown in the present paper, this nerve abnormality is reversible. In itself this must be an argument for demanding the best possible treatment and control of diabetic patients.

To what extent this metabolic abnormality is of significance for the development of clinically demonstrable neuropathy remains to be clarified. Still, it is not unlikely that diabetic angiopathy after some years duration will also contribute to the development of clinical neurological abnormalities (LUNDBAK, 1967).

\section{References}

Azerad, E., G. Boudtr, B. Pepir et J. Lubetsky: Sur une forme particulière amyotrophique de neuropathie diabétique. Presse méd. 69, 1419-1422 (1961).

Bischofr, A.: Diabetes-colloquium, Zürich 1967. To be published.

Eliasson, S.G.: Nerve conduction changes in experimental diabetes. $J$. clin. Invest. 43, 2353-2358 (1964).

-, and A.H. HUGHES: Cholesterol and fatty acid synthesis in diabetic nerve and spinal cord. Neurology (Minneap.) 10, 143-147 (1960).

Elimenterg, M.: Diabetic neuropathy precipitated by diabetic control with tolbutamide. J. amer. med. Ass. 169, 1755-1757 (1959).

FIeID, R.A., and L.C. Adams: Insulin response of peripheral nerve: I. Effect on glucose metabolism and per. meability. Medicine (Baltimore) 43, 275-279 (1964).

Fry, I.K., C. Hardwick, and G.W. Scotr: Diabetic neuropathy: A survey and follow-up of 66 cases. Guy's Hosp. Rep. 111, 113-129 (1962).

GabBay, K.H., L.O. Mrrola, and R.A. Fieud: Sorbitol pathway: Presence in nerve and cord with substrate accumulation in diabetes. Science 151, 209-210 (1966).

Gardand, H.: Diabetic amyotrophy. Brit. med. J. 1955 II, $1287-1290$.

-, and D. TAVERnER: Diabetic myelopathy. Brit. med. J. $1953 \mathrm{I}, 1405-1408$.

GREm IAUM, D.: Observations on the homogenous nature and pathogenesis of diabetic neuropathy. Brain 87, $215-232(1964)$.

GreGERSEN, G.: Diabetic neuropathy: Influence of age, sex, metabolic control and duration of diabetes on motor conduction velocity. Neurology (Minneap.) 17, 972-980 (1967).

- Vibratory perception threshold and motor conduction velocity in diabetics and non-diabetics. Acta med. scand. 183, 61-65 (1968a).

- Latency time, maximal amplitude and electromyography in diabetic patients. Acta med. scand. (1968b). $183,55-60$.

- A study of the peripheral nerves in diabetic subjects during ischaemia. J. Neurol. Neurosurg. Psychiat. 31, $175-181 .(1968 \mathrm{c})$

Gregory, R., and E.L. Lindeey: The diagnosis and management of diabetic neuropathy. Tex. Rep. Biol. Med. 5, 112-144 (1947).

GUYTON, J.D.: The effects of changes in carbohydrate metabolism on motor nerve conduction velocity. Thesis M. Sc. Ohio State University, 1961.

Hetcer, I.H., and S. Hesse: Action of insulin on the respiration of rat sciatic nerve. Lancet 1960 II, 406 - 407.

JoRDAN, W.R. : Neuritic manifestations in diabetes mellitus. Arch. intern. Med. 57, 307-336 (1936).

LUNDBAEK, K.: Altered nerve metabolism and clinical neuropathy in diabetes mellitus. Nord. Med. 78, 946-947 (1967).

Melzak, R., and P.D. Wall: Pain mechanisms. A new theory. Seience 150, $971-979$ (1965).

RAFAelsEN, O.J.: Action of insulin on isolated rat spinal cord. Lancet 1958 II, $941-943$.

REDwoon, D.R.: Diabetic amyotrophy. Importance of good diabetic control. Brit. med. J. 1962 II, 521-522.

Reske-Nitelsen, E., G. Gregersen, and AA. Harimsex: To be published.

SchUMANN, C.R., and S.F. GIIPIN : Diabetic neuropathy: Controlled therapeutic trials. Amer. J. med. Sci. 227, $612-617(1954)$. 
StMrpson J.A.: Conduction velocity of peripheral nerves in human metabolic disorders. Electroenceph. clin Neurophysiol. Suppl. 22, 36-43 (1962).

SkILlekN, P.G., and G. LockHaRT: Optic neuritis and uncontrolled diabetes mellitus in fourteen patients. Ann. Int. Med. 51, 468-475 (1959).

SteINEss, I.: Influence of diabetic status on vibratory perception during ischaemia. Acta med. scand. 170, $319-338$ (1961).
Stewart, M.A., W.R. Sherman, and S. AnthonY: Free sugars in alloxan diabetic rat nerve. Biochem. biophys. Res. Commun. 22, 488-491 (1966).

\section{G. Gregersen, M. D.}

2nd Clinic of Internal Medicine and Department of Neurology Aarhus University School of Medicine Aarhus, Denmark 